\title{
ENSINO E APRENDIZAGEM DE GEOGRAFIA PARA ALUNOS SURDOS: ENTRE A DIMENSÃO VISUAL DA LIBRAS E A LINGUAGEM CARTOGRÁFICA1
}

\author{
Míriam Aparecida BUENO² \\ Pedro Moreira dos SANTOS NETO3
}

\begin{abstract}
RESUMO
O presente artigo pretende apresentar a História da Educação de Surdos e a importância da disciplina de Língua Brasileira de Sinais (Libras) na formação inicial e continuada nos cursos de licenciatura em Geografia, valorizando os aspectos linguísticos, visuais e espaciais dessa língua na relação com o ensino de Geografia, tendo a Cartografia como linguagem mediadora, permitindo assim, a partir da linguagem visual espacial da Libras, propor caminhos para construção dos conteúdos geográficos com os alunos surdos. Após observações de aulas de Geografia em escolas regulares que têm alunos surdos regularmente matriculados, foi possível identificar que existem desencontros linguísticos entre os professores ouvintes e os alunos surdos, e que o trabalho com imagens e mapas possibilitam maior aprendizagem dos conteúdos geográficos com os alunos surdos.
\end{abstract}

Palavras-chave: Ensino de Geografia. Linguagem. Educação Inclusiva. Alunos Surdos. Libras.

\section{GEOGRAFÍA DE ENSEÑNANZA Y APRENDIZAJE PARA ALUMNO SORDOS: ENTRE LA DIMENSIÓN VISUAL DE LIBRAS Y EL LENGUAJE CARTOGRÁFICO}

\section{RESUMEN}

Este artículo pretende presentar la Historia de la Educación para Sordos y la importancia de la disciplina del Lenguaje de Señas Brasileño (Libras) en la formación inicial y continua en los cursos de pregrado en Geografía, valorando los aspectos lingüísticos, visuales y espaciales de este idioma en relación con el La enseñanza de la geografía, con la cartografía como lenguaje mediador, permite, desde el lenguaje visual espacial de Libras, proponer formas para la construcción de contenidos geográficos con estudiantes sordos. Después de las observaciones de las clases de Geografía en las escuelas regulares que han matriculado regularmente a los estudiantes sordos, fue posible identificar que

\footnotetext{
${ }^{1}$ Texto apresentado em palestra realizada no II Congresso Brasileiro de Organização do Espaço (II CBOE) e XIV Seminário do Programa de Pós-Graduação, realizado na cidade de Rio Claro/SP, entre os dias 24 a 28 de março de 2019, intitulado "Soberania e Ciência no século XXI: a decolonialidade do saber como novo paradigma geográfico?".

${ }^{2}$ Professora Associada do Instituto de Estudos Socioambientais (IESA), Universidade Federal de Goiás (UFG).E-mail: miriam.cerrado@gmail.com

3 Doutor em Geografia pelo PPGeo, Instituto de Estudos Socioambientais (IESA), Universidade Federal de Goiás (UFG). E-mail: pedromoreirasn@gmail.com
} 
existen desajustes de idioma entre los profesores de audición y los estudiantes sordos, y que trabajar con imágenes y mapas permite un mayor aprendizaje de los contenidos geográficos con los estudiantes sordos

Palabras clave: Enseñanza de Geografía. Lenguaje. Educación Inclusive. Estudiantes Sordos. Libras

\title{
GEOGRAPHY TEACHING AND LEARNING FOR DEAF STUDENTS: BETWEEN THE VISUAL DIMENSION OF LIBRAS AND CARTOGRAPHIC LANGUAGE
}

\begin{abstract}
This article intends to present the History of Deaf Education and the importance of the Brazilian Sign Language (Libras) discipline in the initial and continuous formation in Geography undergraduate courses, valuing the linguistic, visual and spatial aspects of this language in relation to the Geography teaching, with Cartography as a mediator language, thus allowing, from Libras' spatial visual language, to propose ways for the construction of geographic contents with deaf students. After observations of Geography classes in regular schools that have regularly enrolled deaf students, it was possible to identify that there are language mismatches between hearing teachers and deaf students, and that working with images and maps enable greater learning of geographic contents with deaf students.
\end{abstract}

Keywords: Geography Teaching. Language. Inclusive education. Deaf students. Pounds.

\section{CONTEXTUALIZAÇÃO DA EDUCAÇÃO DE SURDOS}

Iniciaremos nossa caminhada citando Aristóteles, para este Filósofo, a audição era o principal sentido humano para escolarização, dessa forma os surdos, sujeitos privados da audição, não poderiam estudar. Segundo Streiechen (2013, p. 20), "Em alguns países, os Surdos foram lançados ao mar, jogados do alto dos rochedos, abandonados em praças públicas, trancados em asilos ou oferecidos em sacrifícios aos deuses”. Essa ideia permaneceu por diversos séculos até chegar a Idade Média, período em que a Igreja Católica não considerava os surdos como humanos, pois segundo seus preceitos o homem foi criado à imagem e semelhança de Deus, e por não terem audição, os surdos eram descartados.

Nessa época, pensava-se que os surdos por não terem audição e oralidade não poderiam pensar e consequentemente não eram considerados humanos. 
Somente no século XVI foi defendida a tese de que a Surdez não era um impeditivo para a escolarização dos surdos. Esta tese foi defendida pelo médico Gerolamo Cardano, que acreditava que a língua de sinais nada mais é do que a representação da fala4.

Na segunda metade do século XIX, em 1857 foi criado no Brasil o atual Instituto Nacional de Educação dos Surdos, de acordo com Honora (2014, p. 58), "A educação dos Surdos no Brasil teve início com a vinda da família real D. Pedro II, que tinha um neto Surdo, filho da Princesa Isabel, convidou o professor francês Hernest Huet para fundar o Instituto de Surdos Mudos no Rio de Janeiro”. Desse modo, a Língua Brasileira de Sinais teve influência da Língua Francesa de Sinais, uma vez que o professor francês Hernest Huet utilizava do alfabeto manual.

No Brasil, a língua de sinais só foi aceita no século atual, quando em 2002 a Libras foi reconhecida como língua oficial dos surdos por meio da lei no 10.436 de 24 de abril. Com o decreto $\mathrm{n}^{0} 5.626$ de 22 de dezembro de 2005, o Bilinguismo ganhou espaço dentro das unidades escolares ondem possuem alunos surdos matriculados. Essa abordagem prevê que os surdos devem ser escolarizados em Libras e pela Língua Portuguesa na modalidade escrita. Para tanto, é válido mencionar que o aluno surdo deve ser alfabetizado primeiramente em Libras, para depois, com sua língua e pensamento estruturado, aprender a Língua Portuguesa.

Nessa perspectiva, o aluno surdo tem na Libras sua comunicação de instrução e na Língua Portuguesa a modalidade escrita. É interessante que o surdo compreenda o Português, pois estão inseridos em uma sociedade onde se predomina a cultura ouvinte e a Língua Portuguesa, da mesma forma que se torna essencial os ouvintes considerarem e compreenderem os significados dos sinais, tal como se realiza com as palavras.

É válido ressaltar que a Libras é a língua oficial de aproximadamente 10 milhões de surdos (IBGE, 2010) e muitos desses surdos já passaram e/ou ainda vão passar pela Educação Básica. Diante dessa situação construímos os seguintes questionamentos: De que forma as categorias de análise da Geografia

4 Na língua oral, a escrita é a representação da fala, enquanto que na língua de sinais o sinal representa a fala. 
poderiam ser desenvolvidas com os alunos surdos a partir dos temas e conteúdos escolares?

Segundo Deliberato (2000), os surdos têm um aumento de amplitude do componente visual oriundo das regiões temporal e frontal do cérebro, refletindo a influência dominante de aderências visuais em células multimodais. A autora explica que o surdo depende somente do campo visual para monitorar novas informações, diferente do ouvinte que além do campo visual se utiliza do sentido auditivo. Um dos caminhos para trabalhar com alunos surdos em sala de aula perpassa pela valorização da percepção do aluno surdo, pois a leitura visual espacial (mapas e imagens) contribui para aprendizagem de Geografia.

De acordo com Demo (2005), nenhum sujeito é analfabeto, uma vez que todos têm alguma identidade histórica e cultural e dominam alguma linguagem. Neste contexto, o professor deve conhecer as motivações e os contextos culturais dos alunos surdos para estabelecer um relacionamento de confiança entre eles, possibilitando dessa forma construir o conhecimento do aluno na relação científico-cotidiano.

Concordamos com Freire (1989) quando o mesmo escreve que os alunos não devem memorizar mecanicamente a descrição dos objetos, mas compreender a sua significação profunda, ou seja, os conteúdos devem ser mais carregados de significações e experiência existencial dos alunos, no caso dos alunos surdos, a inclusão perpassa por considerar seu contexto social, linguístico e cultural.

Para Libâneo (2008, p. 41), devemos valorizar "a importância de se considerar os motivos dos alunos e os contextos socioculturais da aprendizagem". Para tanto se torna fundamental compreender o processo segregatício em que o surdo historicamente foi submetido, conhecer as especificidades dos alunos surdos e quais são suas diferenças em relação aos alunos ouvintes e os desdobramentos social, biológico, linguístico e cultural oriundo da privação da audição e pelo uso da língua de sinais. 


\section{DIMENSÃO VISUAL-ESPACIAL DA LIBRAS E A INCLUSÃO ESCOLAR DE ALUNOS SURDOS}

A contextualização histórica da educação de surdos nos dá base para compreendermos a importância da Libras para escolarização e estruturação do pensamento, continuaremos nossa caminha em direção a linguagem visual espacial da Libras e sua apropriação para o ensino de Geografia, vislumbrando desenvolver reflexões que perpassam pela construção da autonomia socioespacial do aluno surdo a partir da sua leitura espacial de mundo.

Qual o termo correto para tratar uma pessoa que não tem audição? Deficiente Auditivo? Surdo? Surdo-Mudo? Mudinho? Pessoa portadora de Surdez? A pessoa que tem privação da audição pode ser tratada como Deficiente Auditivo ou como Surda. Para Cormedi (2010, p.7), "O conceito de Surdo como pessoa com deficiência passou a ser combatida pela comunidade surda, porque esta considera a pessoa com surdez como diferente e não deficiente".

Neste contexto, temos que entender a diferença do surdo para compreendê-lo e assim pensar em metodologias de ensino, adotando a linguagem visual espacial como principal caminho para comunicação, representação e linguagem. De acordo com Almeida (2014, p. 3):

O drama dos Surdos é menos ligado à sua enfermidade do que às razões psicológicas que rapidamente se transformam em efeitos patológicos. A causa profunda desse drama encontra-se ligada à incompreensão da sociedade que não o vê como diferente e, sim, como deficiente.

Do ponto de vista jurídico, a pessoa é considerada surda legalmente, segundo o decreto $\mathrm{n}^{0} \cdot 5 \cdot 626$, de 22 de dezembro de 2005 , que regulamenta a lei $\mathrm{n}^{\mathrm{o}}$. 10.436, de 24 de dezembro de 2002, que dispõe sobre a Libras:

Art. 2 Para os fins deste Decreto, considera-se pessoa surda aquela que, por ter perda auditiva, compreende e interage com o mundo por meio de experiências visuais, manifestando sua cultura principalmente pelo uso da Língua Brasileira de Sinais Libras.

Parágrafo único. Considera-se deficiência auditiva a perda bilateral, parcial ou total, de quarenta e um decibéis (dB) ou mais, aferida por audiograma nas frequências de $500 \mathrm{~Hz}$, $1.000 \mathrm{~Hz}, 2.000 \mathrm{~Hz}$ e $3.000 \mathrm{~Hz}$. (Hertz) 
Diante do apresentado, a lei define o Deficiente Auditivo por perda igual ou superior a $41 \mathrm{~dB}$ aferido por exames específicos, reconhecendo que o surdo interage com o mundo pelas experiências visuais, comunicando-se pelo uso da Libras.

Partindo da perspectiva que o sujeito, ele próprio, é o movimento e a vida que pode transformar o seu mundo, considera-se então o posicionamento desse sujeito enquanto surdo e não Deficiente Auditivo. Segundo Libâneo (2008, p. 31), devemos considerar as "[..] condições de quem aprende e os contextos socioculturais em que a aprendizagem ocorre", desse modo, compreender o sujeito em sua perspectiva histórica é fundamental para entendê-lo, pensando o mundo dos surdos a partir de seu lugar, das suas relações sociais de produção da vida.

Conforme Honora (2014, p. 25), a "Pessoa com deficiência auditiva é aquela cuja audição está prejudicada a ponto de dificultar, mas não impedir a compreensão da fala. São pessoas que se comunicam de forma oral”. Essa pessoa poderá fazer uso de Aparelhos de Amplificação Sonora Individual, pois apresenta perde leve ou moderada da audição. Ainda a mesma autora (2014, p. 26) relata que, "Pessoa com Surdez é aquela cuja audição está prejudicada a ponto de impedir a compreensão da fala através do ouvido, com ou sem o uso de um Aparelho de Amplificação Sonora Individual”. Geralmente a pessoa surda é usuária da Libras e apresenta perda auditiva profunda.

A perda auditiva poderá ocorrer por causas no pré-natais5 (durante a gestação); perinatais ${ }^{6}$ (momento do parto até um mês após o nascimento) e pósnatais7 (um mês após o nascimento até o último dia de vida). Dessa forma, a Surdez pode ocorrer desde a vida uterina até a morte do sujeito. Assim, a Surdez pode ser Congênita (quando o sujeito nasce surdo) e/ou Adquirida (nasce ouvinte e perde a audição durante a vida).

As línguas de sinais possuem gramática própria e não são universais, no caso da Libras, para sua efetiva compreensão é necessário conhecer os seus

\footnotetext{
${ }^{5}$ Consumo de álcool, drogas ototóxicas, exposição da mãe à irradiação por Raio X, fatores genéticos, fatores hereditários, carência alimentares, entre outros.

${ }^{6}$ Prematuridade, pós-maturidade, incompatibilidade sanguínea, anóxia, trauma no parto, entre outros.

7 Sarampo, caxumba, meningite, infecção de ouvido, idade avançada, exposição intensa por longos períodos aos ruídos, entre outros.
} 
parâmetros linguísticos ${ }^{8}$, a semântica, a sintaxe, a morfologia, enfim, sua estrutura. Para Honora (2014, p. 67), "As línguas de sinais em nada são inferiores às línguas orais. Através das línguas de sinais pode-se dialogar em qualquer assunto: política, economia, filosofia, literatura, ciência, sentimentos, poesias, piada, teatro, filmes, entre outros".

No Brasil, a Libras é a língua oficial e o principal meio de comunicação do surdo, isto não significa que a Língua Portuguesa deva ser desconsiderada, entretanto, a Libras deve ser a primeira língua do aluno surdo para sua escolarização e a Língua Portuguesa na modalidade escrita. De acordo com Honora (2014, p. 77), "Demoramos em média três anos para aprender Libras e a melhor maneira é com um professor Surdo para que, além de aprender a língua, ter contato com a comunidade e Cultura Surda".

Isso significa que o professor de Geografia não vai aprender a Libras em um curso de 64 horas na formação inicial 9 , tendo que manter os estudos na formação continuada para o mínimo de compreensão desse sistema complexo linguístico. A Libras não deve ficar restrita somente aos surdos e a Língua Portuguesa não pode ficar restrita somente aos ouvintes, mesmo porque o conhecimento é produzido no individual e coletivo por meio de diferentes linguagens.

As escolas regulares têm a Língua Portuguesa como língua de instrução predominante, dessa maneira como os surdos vão estudar em uma língua que não é a sua? Segundo Streiechen (2013, p. 116), "precisamos admitir que a escola tem legitimado a exclusão, principalmente dos grupos em desvantagem, mesmo quando procura inserir alunos nas classes regulares, mas sem apoios necessários".

Primeiramente, deve-se respeitar as particularidades e as especificidades linguísticas e culturais dos alunos surdos para educação inclusiva e compreensão efetiva da Libras. Ainda Streiechen (2013, p. 122):

Portanto, antes de tentarmos "socializar" e "integrar" os Surdos à cultura ouvinte, devemos tentar entender o modo de agir e de

8 Configuração Manual, Orientação, Ponto de Articulação, Movimento e Expressão nãomanuais.

9 A Libras se tornou obrigatório nos cursos de licenciatura com o Decreto ${ }^{0} 5.626$, de 22 de dezembro de 2005 . 
pensar dessas pessoas. Não podemos tentar educar uma pessoa ou uma comunidade levando em consideração apenas o nosso meio ou o nosso modo de ser. (STREIECHEN, 2013, p. 122).

O ouvinte aprende as palavras pela audição ao relacionar as palavras com os fonemas, diferente dos surdos que aprendem pelo canal visual por causa da ausência da audição e por isso não se apoiam nos fonemas como os ouvintes, mas sim, na imagem da palavra e do sinal para entender o significado.

Os professores devem ter clareza que o aluno surdo fala em uma língua e escreve em outra, isso deve ser levado em consideração na produção textual ${ }^{10}$. No caso dos surdos, não é somente falar uma língua e escrever em outra, é se apropriar de uma língua oral e auditiva, quando não se tem audição e consequentemente a oralidade.

Para Pereira (2013, p. 212), "Na lógica de promoção de justiça, todo sistema educacional deveria assegurar uma educação adequada com um currículo que aponte à pertinência, à inclusão e à justiça”, entretanto a realidade da sala de aula ainda continua distante dos alunos surdos, na prática as aulas valorizam a língua oral e a escrita.

A comunicação é premissa para o processo de construção do conhecimento individual e coletivo, portanto, se torna fundamental que o professor de Geografia compreenda que a Libras é o meio de comunicação do aluno surdo e que essa língua se manifesta na modalidade visual espacial, assim dessa maneira, o professor deverá valorizar essa linguagem, trabalhando os conteúdos geográficos nessa perspectiva.

De acordo com Honora (2014, p. 100), "Como o aluno com Surdez tem uma melhor captação de estímulos visuais, por ter apurado sua atenção nesta área, cabe ao professor oferecer materiais ricos de estímulos visuais e usar a Língua de Sinais”. Neste contexto, é preciso olharmos para o mundo onde as mãos também falam e encararmos a Geografia enquanto possibilidade para compreender e interpretar o mundo por meio das relações sociais que produzem o espaço geográfico em que vivemos.

Neste contexto, se torna essencial que o professor considere o aluno surdo como sujeito produtor do espaço em que vive, considerando seus

${ }^{10}$ Conforme Decreto ${ }^{\circ} 5626$ de 22 de dezembro de 2005 
respectivos conhecimentos espaciais, valorizando o seu cotidiano na produção de mapas dos espaços construídos por eles próprios, pois a leitura visual espacial do aluno surdo é mediado pela apropriação espacial nas relações sociais que vivem na cidade. Segundo Richter (2013, p, 112), “[...] no trabalho escolar da Geografia, torna-se importante que o professor utilize os conceitos científicos que possibilitam ao aluno interpretar a realidade sob a perspectiva da produção do espaço", a partir da vivência, os conceitos de espaço geográfico, lugar, paisagem, território e região ganham significados.

Partimos da mesma perspectiva que Pimenta (2012, p. 24), ao escrever que o trabalho do professor deve ser encarado enquanto mediação dos processos constitutivos da cidadania dos alunos. De acordo com a autora (Op.Cit), "[...] não basta produzir conhecimento, mas é preciso produzir as condições de produção do conhecimento". E quais são as atuais condições didáticas-pedagógicas que os professores de Geografia proporcionam para os alunos surdos e com eles estão inseridos na Educação Básica?

Tanto o professor quanto o aluno surdo não têm uma preparação educacional adequada ao longo da vida, o professor na Educação Básica e superior e o aluno surdo nas séries iniciais até a universidade, então os erros são dos professores e alunos surdos? Penso que não, é preciso que mude o modo que a Educação é pensada neste país, valorizando os educadores e alunos, onde a Educação Básica e superior tenha reais condições de serem agentes transformadores de vidas e não instrumentos ideológicos que agem na finalidade de manter o domínio das estruturas e sociedade.

Diante do exposto, temos diversos problema em escala local, regional, nacional e global que precisam ser superados. Para Machado (2008, p. 78), "Pouco adianta a presença de Surdos se a escola ignora sua condição histórica, cultural e social", assim devemos considerar a história dos surdos e os próprios sujeitos como parte integrante da construção do conhecimento.

Dentro da sala de aula, considerando a relação professor-aluno, o problema se realiza em diversos níveis e um deles é que o aluno surdo chega ao Ensino Fundamental II e Ensino Médio com dificuldades na modalidade escrita do Português, enquanto que os professores não dominam a Libras. 
Então, existem desencontros comunicativos entre os sujeitos. Para superar essa questão, os alunos surdos têm o direito de ter Tradutor Intérprete de Libras durante as aulas para que possam ter o mínimo de condições para o acesso às informações e permanência nas escolas. Segundo Honora (2014, p. 121) "O professor é o responsável pelo conteúdo da sua aula, o intérprete é o responsável pela tradução do assunto tratado pelo professor para o aluno com Surdez", porém a falta de intérpretes em salas de aula faz com que os alunos surdos não tenham acesso aos conteúdos em sua língua.

Outro caminho que podemos realizar na função de professores, perpassa pelos mapas como recurso pedagógico para construção da autonomia socioespacial do aluno surdo a partir das relações cotidianas e da representação do espaço vivido, pensando o mapa mental como possibilidade de interpretação da leitura espacial, pois de acordo com Pontuschka, Paganelli e Cacete (2009), os mapas mentais representam as práticas sociais dos sujeitos na percepção e estruturação de seu espaço.

\section{ALGUMAS CONSIDERAÇÕES SOBRE O ENSINO DE GEOGRAFIA PARA ALUNOS SURDOS}

Conhecendo a realidade do aluno surdo, sabe-se que o aspecto visual é de fundamental importância para comunicação do surdo com o mundo, pois as formas de receberem os estímulos do ambiente se realiza pelo canal visual. $\mathrm{O}$ surdo desenvolve forçosamente os aspectos visuais, utilizando-se da Libras como meio de comunicação e linguagem visual espacial para realização das relações cotidianas, nessa perspectiva que poderão ser trabalhados os conteúdos geográficos. Segundo Streiechen (2013, p. 28):

As línguas de sinais são realizadas no espaço e percebidas visualmente, ou seja, usam o espaço e as dimensões que ele oferece na constituição de seus mecanismos fonológicos, morfológicos, sintáticos e semânticos para veicular significados, os quais são percebidos pelos seus usuários por meio das mesmas dimensões espaciais. (STREIECHEN, 2013, p. 28).

Neste contexto, a percepção e consciência espacial do aluno surdo é mediada pela apropriação espacial nas relações sociais que vivem na cidade. Para Carlos (2007, p. 26), "O lugar é o mundo vivido, é onde se formulam os 
problemas da produção no sentido amplo, isto é, o modo como é produzida a existência social dos seres humanos". A partir dessa possibilidade e da vivência, a categoria espaço geográfico e os conceitos de lugar, ganham significados para a vida dos alunos.

A apropriação espacial da cidade pelo aluno surdo, seja pelo sentido que ele produz o espaço ao viver a cidade nos diferentes níveis de relações cotidianas, tais como: escola, lazer, habitação, saúde, trabalho, sociabilidade, se colocam também para pensar o direito aos espaços e à diferença. Partindo dessa perspectiva, podemos pensar enquanto atividade prática geográfica com os alunos surdos, trabalhar a descrição para além do enunciado da morfologia terrestre, dos componentes artificiais e/ou naturais (SANTOS, 1994), uma descrição que evidencie o movimento das coisas que as dão vida.

Neste sentido, um exemplo de atividade que o professor de Geografia pode utilizar com os alunos surdos é a representação e descrição da paisagem para compreensão do espaço geográfico e sua produção pelos grupos sociais, a fim de superar algumas das dificuldades que perpassam pelo tema abordado, considerando a realidade concreta dos alunos na construção do conhecimento geográfico, pois de acordo com Santos (1994, p. 71), "A paisagem é materialidade, formada por objetos materiais e não-materiais".

Para Cavalcanti (2014, p. 31), "A paisagem, costuma-se dizer, é uma chave importante para o entendimento da cidade, ela traz elementos para compreender o espaço urbano, que é formado por suas formas, mas também por seu conteúdo, por sua história [...]". Pode-se pensar a construção da autonomia socioespacial dos alunos surdos na perspectiva da práxis, numa relação dialética entre a teoria e a prática nas relações socioespaciais destes alunos com a cidade, pois segundo Couto (2011, p. 43):

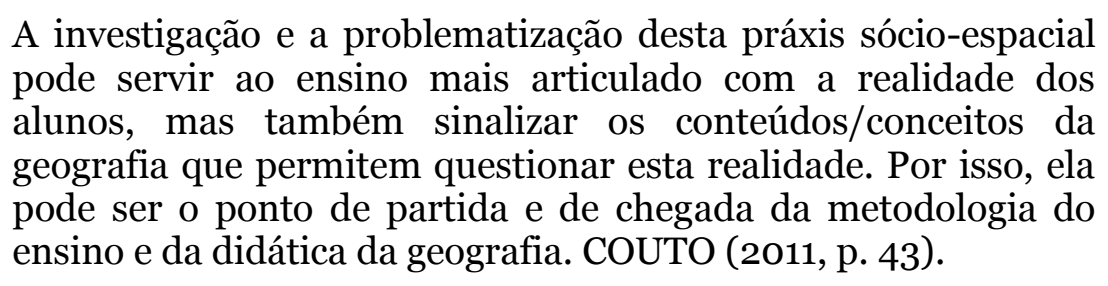

Pensar o mundo nas suas relações socioespaciais é pensar o mundo nas diferentes linguagens, entre elas a Libras. Nessa abordagem, se torna crucial 
pensar as problemáticas cotidianos dos alunos surdos no nível espacial, compreendendo que o espaço geográfico é produzido por eles próprios, assim, os alunos surdos não sentiram excluídos do processo de ensino e aprendizagem e compreenderiam o espaço como um produto social e em constante movimento.

Segundo Harvey (2012, p. 20), "Os espaços e os tempos da representação que nos envolvem e nos rodeiam em nossa vida cotidiana afetam tanto nossas experiências diretas quanto nossa interpretação e compreensão", o que possibilita a compreensão dos processos reais das práticas socioespaciais desses alunos.

Cavalcanti (2014, p. 32), ao tratar da cidade, escreve que "Nela se expressa um modo de vida urbano: esse espaço urbano é condição e produto das relações sociais que ali se estabelecem". Neste contexto, a cidade possibilita estudar o cotidiano e a realidade vivenciada, sendo elementos fundamentais para construção da autonomia socioespacial dos alunos surdos, pois a relação entre a teoria e a prática nas relações sociais de produção do espaço geográfico possibilitam colocar a pesquisa em movimento com o sujeito.

Segundo Callai (2010), a educação geográfica vai para além da sala de aula, ela pretende estabelecer as bases de um conhecimento que seja duradouro e que contribua para a formação dos sujeitos, por isso não se pode simplesmente passar os conceitos aos alunos, pois os lugares são construídos no cotidiano de nossas vidas. Desta forma, a categoria espaço geográfico e o conceito de lugar devem ser construídas por meio do trabalho com a realidade dos alunos. Para Callai (2009, p. 187), "Trabalhar com os conceitos específicos da geografia e com as categorias de análise é fundamental para desenvolvimento do olhar espacial e fazer a análise geográfica".

A produção do conhecimento geográfico não se realiza apenas na educação formal, uma vez que a Geografia estuda o espaço por meio das relações sociais de produção. Desse modo, a Geografia enquanto espacialidade das relações em sua dimensão concreta e simbólica se desenvolve dentro e fora do ambiente escolar. Conforme Cavalcanti (2014, p. 29), "A aposta que tenho investido é a de considerar que a Geografia na escola deve ter um "link" com a 
Geografia do aluno, na convicção de que só assim ele terá alguma relação de sentido com a matéria de ensino formalizada”.

Outro autor que corrobora com essa perspectiva é Pereira (2013, p. 203), para este, “A geografia escolar, então, deve potenciar a relação com a geografia disciplinar trazendo os exercícios formalizadores que permitam robustecer a cognição do espaço (em qualquer de seus níveis)”. Por conseguinte, é importante considerar o cotidiano do aluno surdo enquanto sujeito produtor do espaço geográfico para estudar as transformações socioespaciais que vivenciam, pois a percepção do espaço deste aluno surdo, possibilita explorar, inserir e construir a sua Geografia.

O lugar como estabelecimento das relações cotidianas ajuda a pensar o espaço geográfico. Corrêa (2012) cita Lefebvre ao escrever que o espaço geográfico é a reprodução das relações sociais de produção da sociedade. Santos (1985), também inspirado em Lefebvre, na concepção de espaço social, argumenta que, para compreender os fenômenos espaciais em sua totalidade, o espaço deve ser analisado a partir das categorias: forma, função, estrutura e processo.

Logo, a partir da concepção de Lefebvre (2008), pensamos o espaço como reprodução das relações sociais de produção da sociedade, sendo lugar e meio da prática social. Portanto, pensar o espaço a partir de Lefebvre significa compreender o espaço nas dimensões do concebido, do percebido e do vivido, considerando o espaço socialmente construído.

Para Cavalcanti (2011, p. 195), “O espaço geográfico é, desse modo, construído intelectualmente como um produto social e histórico, que se constitui em ferramenta que permite analisar a realidade”. Neste contexto, torna-se fundamental que o professor pense o movimento da realidade e da produção do espaço geográfico a partir do cotidiano do aluno Surdo na perspectiva do conhecimento científico, considerando as relações sociais presentes na cidade mais do que a própria morfologia.

Segundo Santos (1996, p. 75), "A configuração espacial é um dado técnico, enquanto o espaço geográfico é um dado social”, sendo um dos caminhos a ser percorrido para almejar o desenvolvimento da autonomia socioespacial do aluno surdo, considerando o mapa enquanto linguagem, 
representação e comunicação, não sendo o produto final a produção cartográfica, mas o caminho para pensar as relações sociais de produção da vida destes alunos surdos.

Assim, a compreensão do sujeito e da sua história, da sua língua e especificidades se torna crucial para entendê-lo. Logo, temos na Geografia ciência de dimensão socioespacial - a possibilidade do ensino e aprendizagem da Geografia escolar para alunos surdos, tendo como perspectiva, a valorização da linguagem visual espacial e sua relação multiescalar com os conceitos de espaço geográfico, lugar, paisagem, território e região.

Conclui-se que a Educação de surdos é algo recente no Brasil e ganhou forças com a aprovação da Libras como língua oficial no ano de 2002 e a obrigatoriedade do ensino da Libras nos cursos de licenciatura a partir de 2005. Neste sentido, é preciso que avancemos do ponto de vista da legislação para dentro das salas de aula, e a Geografia enquanto ciência e disciplina poderá contribuir de maneira satisfatória no ensino e aprendizagem dos seus conteúdos por meio de imagens e mapas, pois a linguagem desses recursos está em consonância com a modalidade visual espacial da Libras.

\section{REFERÊNCIAS}

ALMEIDA, Elizabeth Oliveira Crepaldi de. Leitura e Surdez: um estudo com adultos não oralizados. - 2. ed - Rio de Janeiro: Revinter, 2012.

BRASIL. Decreto $\mathrm{n}^{\mathrm{o}} \cdot 5.626$, de 22 de dezembro de 2005. Regulamenta a Lei $\mathrm{n}^{\mathrm{o}}$ 10.436, de 24 de abril de 2002, que dispõe sobre a Língua Brasileira de Sinais Libras, e o art. 18 da Lei no 10.098, de 19 de dezembro de 2000. Diário Oficial [da] República Federativa do Brasil, Brasília, DF, 23 dez. 2005. Disponível em: http://www.planalto.gov.br/ccivil_03/_ato2004-2006/2005/decreto/d56 26.htm. Acesso em: 07 jan. 2017.

CALLAI, Helena Copetti. A Geografia Ensina: os desafios de uma educação geográfica. In: MORAIS, Eliana Marta Barbosa de, MORAES, Loçandra Borges de. Formação de Professores: conteúdos e metodologias no ensino de geografia. - Goiânia: NEPEG, 2010 (Goiânia: E.V.) p. 15-37.

CALLAI, Helena Copetti. O Lugar e o Ensino Aprendizagem da Geografia. In: PEREIRA, Marcelo Garrido (orgs.). La Espessura Del Lugar: reflexiones sobre el espacio em el mundo educativo. Santiago: Universidad Academia, 2009. 
CARLOS, Ana Fani Alessandri. O lugar no/do Mundo. São Paulo: Labur, 2007.

CAVALCANTI, Lana de Souza. A metrópole em foco no ensino de geografia: o que/para que/para quem ensinar? In: ASSIS PAULA, Flávia Maria de; CAVALCANTI, Lana de Souza; SOUZA, Vanilton Camilo de. (Org.). Ensino de Geografia e Metrópole. 1a. ed. Goiânia - Goiás: Gráfica e Editora América Ltda. v. 1, 2014.

CAVALCANTI, Lana de Souza. Ensinar Geografia para autonomia do pensamento. In: Revista da Anpege, V. 7, n. 1 (edição especial), 2011. p. 193203.

CORMEDI, Maria Aparecida (Org.) Estudos sobre a Deficiência Auditiva e Surdez. Brasília-DF, 2010.

CORREA, Roberto Lobato. Espaço: um conceito-chave da Geografia. In: CASTRO, Iná Elias de; GOMES, Paulo Cesar da Costa; CORRÊA, Roberto Lobato. Geografia: conceitos e temas. $15^{\mathrm{a}}$ ed. Rio de Janeiro: Bertrand Brasil, 2012.

COUTO, Marco Antônio Campos. Método Dialético na Didática da Geografia. In: CAVALCANTI, Lana de Souza [et al] (orgs.). Produção do Conhecimento e Pesquisa no Ensino de Geografia. Goiânia: ed. Da PUC Goiás/NEPEG, 2011.

DELIBERATO, Débora. Aspectos da percepção visual em pré-escolares surdos e ouvintes. Tese. Campinas, 2000.

DEMO, Pedro. O Desafio de educar pela Pesquisa na Educação Básica. In:

DEMO, Pedro. Educar pela Pesquisa. Campinas: Autores Associados, 2005.

FREIRE, Paulo. A importância do ato de ler. In: FREIRE, Paulo Freire. A importância do ator de ler: em três artigos que se completam. São Paulo: Autores Associados/Cortez, 1989.

HARVEY, David. O espaço como palavra-chave. GEOgraphia, Vol. 14, n. 28, 2012.

HONORA, Márcia. Inclusão educacional de alunos com surdez: concepção e alfabetização. São Paulo: Cortez, 2014.

LEFEBVRE, Henri. Espaço e política. Belo Horizonte: EdUFMG, 2008.

LIBÂNEO, José Carlos. Pensar e atuar em Educação Ambiental: questões epistemológicas e didáticas. In: ZANATTA, Beatriz Aparecida; SOUZA, Vanilton Camilo de. (orgs.). Formação de Professores: reflexões do atual cenário sobre o ensino da Geografia. Goiânia: Vieira/NEPEG, 2008. 
MACHADO, Paulo Cesar. Política Educacional de Integração/Inclusão: um olhar do egresso Surdo. Florianópolis: Ed. UFSC, 2008.

PEREIRA, Marcelo Garrido. Conhecer e Aprender o Espaço: considerações previas a um processo de intervenção pedagógica. In: CAVALCANTI, Lana de Souza. (org.). Temas da Geografia na Escola Básica. Campinas: Papirus, 2013 .

PIMENTA, Selma Garrido. Formação de Professores: identidade e saberes da docência. In: PIMENTA, Selma Garrido (org.). Saberes Pedagógicos e Atividade Docente. São Paulo: Cortez, 2012.

PONTUSCHKA, Nídia Nacib; PAGANELLI, Tomoko Lyda; CACETE, Núria Hanglei. Para Ensinar e Aprender Geografia. $3^{\mathrm{a}}$ ed. - São Paulo: Editora Cortez, 2009.

RICTHER, Denis. Os Desafios da Formação do Professor de Geografia: o Estágio Supervisionado e sua articulação com a escola. In: SILVA, Eunice Isaías \& PIRES, Lucineide Mendes (orgs.). Desafios da Didática da Geografia. Goiânia: Ed. PUC Goiás, 2013.

SANTOS, Milton. Espaço e método. São Paulo: Nobel, 1985.

SANTOS, Milton. Metamorfoses do espaço habitado. $3^{\text {a }}$ Edição. São Paulo: Hucitec, 1994.

SANTOS, Milton. Natureza do espaço. São Paulo: Nobel, 1996.

STREIECHEN, Eliziane Manosso. Libras: aprender está em suas mãos. 1. ed Curitiba, PR: CRV, 2013. 